\title{
Cambrian Ordovician sedimentary facies and its evolution in Tadong area
}

\author{
Ding Hansheng ${ }^{1, *}$ \\ ${ }^{1}$ Exploration and Development Science Research Institute of Daqing Oilfiled Company Ltd., Daqing 163712, China
}

\begin{abstract}
In order to clarify the sedimentary development law under the Cambrian Ordovician regional stratigraphic framework in Tadong area, and lay a theoretical foundation for further oil and gas exploration in the study area. The distribution, characteristics and evolution of main sedimentary facies belts of Cambrian Ordovician are studied by means of drilling core observation, cast thin section identification, logging curve feature analysis, seismic profile and well connection profile. The results show that the Cambrian middle lower Ordovician in Tadong area is equivalent to a second-order sequence and can be further divided into 12 thirdorder sequences. Each third-order sequence is mainly composed of transgressive and highstand tracts. Carbonate platform margin beach facies and Reef (mound) beach complex facies are favorable reservoir development facies belts in this area; Under the regional stratigraphic framework, three types of sedimentary facies can be identified in Cambrian Ordovician, and a total of 10 subfacies are developed; The evolution of sedimentary facies is mainly controlled by the rise and fall of sea level, which is characterized by the migration of platform margin facies and the change of platform facies.
\end{abstract}

\section{Introduction}

Carbonate strata are developed in Cambrian-Ordovician in Tarim Basin. Through the research work done by predecessors on sedimentary facies of CambrianOrdovician in Tarim Basin [1-14] provided guidance on the discovery of many large-scale oil and gas fields of reef-beach complex, such as Tazhong slope break zone and Shunnan slope, which indicates that Tarim Basin has a good exploration prospect. After Daqing Oilfield took over the Tadong block at the end of 2012, TJ13, TJ13-2, TJ13-3 and TJ13-4 wells were drilled in Gucheng platform one after another, and high-yield industrial gas flow was obtained, showing the exploration potential of platform facies in Tadong area. However, due to the lack of drilling in Tadong area in the early stage, little study has been done on the development law of sedimentary facies belt. In such case, in order to further accelerate the exploration efforts in Tadong area and effectively guide the exploration deployment, on the basis of previous studies, this paper makes full use of a large number of outcrops, drilling and seismic data, and systematically compiles the Cambrian-Ordovician sedimentary facies under the second-order sequence framework in Tadong area, and clarifies the development characteristics and evolution law of sedimentary facies.

The study area is located in the eastern region of Tarim Basin, part of the Tarim plate, bounded by Kuruktag in the north, southeast bulge in the south, TJ16 well in the west and Laokaiping in the east, with an area of about $12 \times 104 \mathrm{~km} 2$. The north and south of the study area are controlled by Cherchen fault and Kongquehe fault respectively, and can be divided into six secondary structural units, such as Gucheng low uplift, Tadong low uplift, Lop Nur uplift, part of Manjiaer sag, Yingjisu sag and Kongquehe slope (Figure 1). TJ13 well and TJ13-2 well have obtained industrial high-yield gas flow in dolomite reservoir of Middle and Lower Ordovician, while well TJ15 well and TJ8 well have seen better oil and gas in Cambrian, indicating that carbonate reservoir of Cambrian-Middle and Lower Ordovician is one of the main oil and gas exploration reservoirs in this area at present.

During Cambrian-Early Ordovician, stable carbonate platform-basin sedimentary system was developed in Tadong area, and its main body was located in deep water basin area, where undercompensated semideep sea-deep sea basin facies was developed, and the deposited dark mudstone was one of the most important source rocks in the basin. Two carbonate platforms were developed on east and west sides of the basin respectively, platform slopes and platform margins were developed between the platforms and the basin, and reef-beach deposits developed in the platform margins and platforms are favorable reservoirs. At the end of Early Ordovician, due to the subduction and collision of the mid-Kunlun island arc in the southern margin of the basin, the basin began to be in a compressional tectonic environment, and Tazhong, Tabei, Bachu and Tadong uplifts began to take shape, while the amplitude of Tadong uplift was relatively small. Turbid flow basins are developed in Tadong area, and a set of dark mudstone is deposited, which can be used as potential source rocks and favorable caprocks in Tadong area.

\footnotetext{
* Corresponding author: dinghansheng@petrochina.com.cn
} 


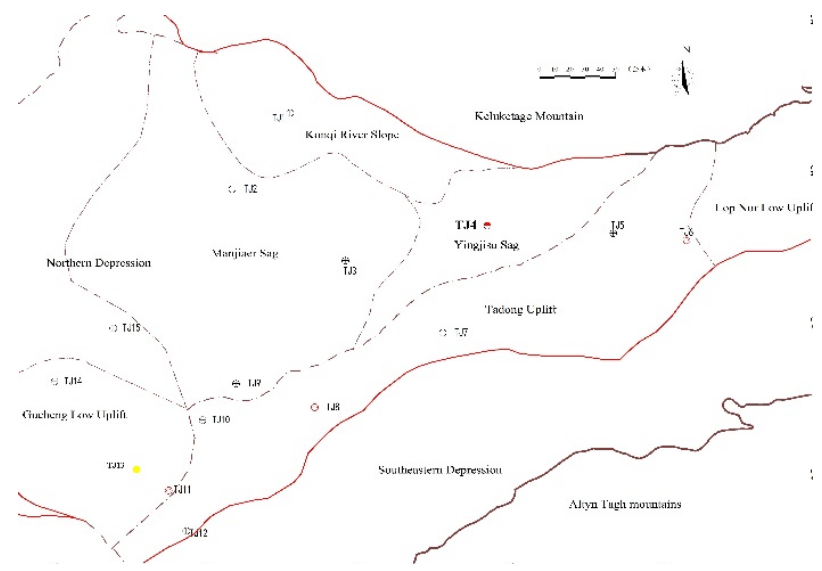

Fig. 1. Geographical location and structural map of the study area.

\section{Sequence stratigraphic framework}

The rising and falling rate of sea level obviously controls the carbonate platform structure. When the sea level rises rapidly, accretion and retrogradation platform structures are usually formed and the platforms may be even submerged, and the platform edges remain stationary or migrate towards the platform. When the sea level drops rapidly, platform structures which constantly migrates to the sea and with a foreset-and-decline stacking pattern are often formed. Therefore, on the basis of fully combining the previous basin research results, well-seismic analysis and systematic tracking and interpretation of seismic profiles, the sedimentary sequence division scheme of Cambrian-Middle and Lower Ordovician was determined, and the sequence stratigraphic framework and system tract composition style were established. The MiddleLower Ordovician in the region is equivalent to the second-order sequence (Figure 2), which is generally composed of a large transgression-regression cycle. The middle and lower Ordovician in eastern Tarim area can be divided into seven third-order sequences, namely SQ_O1p-1, SQ_O1p-2, SQ_O1y-1, SQ_O1y-2, SQ_O1y3, SQ_O1y-4 and SQ_O2y. Each sequence is mainly composed of transgressive and high-level domains, and condensed segments are developed during the maximum transgressive period. Carbonate platform beaches are widely developed in high-level domains of each sequence, which is a favorable reservoir development period. SQ_O1y-4 is generally characterized by relative transgression. The CAMBRIAN in Tadong area is equivalent to the second-order sequence, which is generally composed of a large transgression-regression cycle, and can be divided into five third-order sequences, namely SQ_C1, SQ_C2, SQ_C3-1, SQ_C3-2 and SQ $\mathrm{C} 3-3$. Each sequence is mainly composed of transgressive and high-level domains. Carbonate platform beaches in SQ_C3 sequences are widely developed, which is a favorable reservoir development period, and is generally characterized by retrogression sedimentation. The sequence division of Middle and Lower Ordovician in Tadong area can be compared with the previous research results in Tazhong and Tabei.

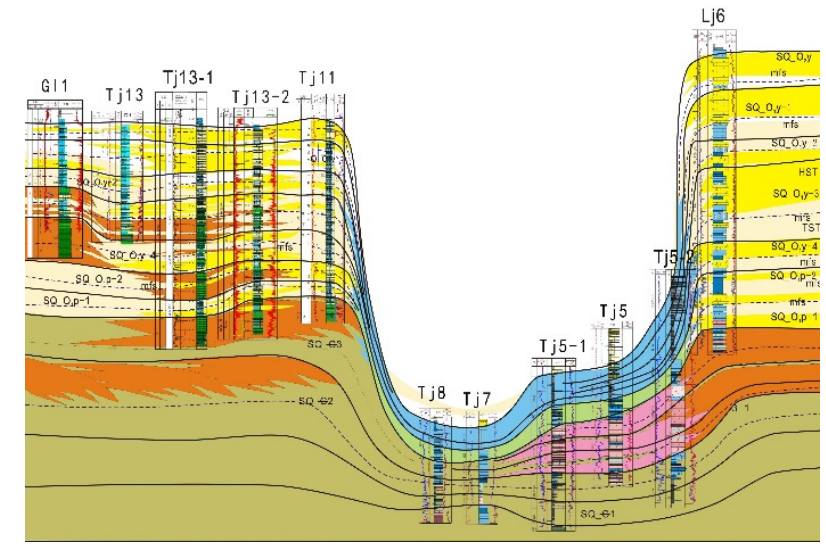

Fig. 2. Sequence framework and system tract composition of Gucheng-Luoxi in comparison of Ordovician series wells in Tadong area.

\section{Distribution and characteristics of sedimentary facies belt}

Guided by sequence framework, according to drilling cores, microscopic observation, logging curve characteristic analysis and macroscopic seismic facies interpretation, three types of sedimentary facies are identified, which are basin facies, platform margin facies and platform facies. Ten subfacies are developed, including open platform, limited-semi-limited platform, platform margin reef-beach complex and mud mound, platform margin front slope, shallow sea shelf and deep water basin. The sedimentary facies evolution model is comprehensively established, and the distribution and characteristics of main sedimentary facies belt in Cambrian-Ordovician Gucheng platform- Luoxi platform of Tadong is systematically summarized.

\subsection{Basin facies}

The basin facies is located at the front end of the platform edge slope facies, and distributed in a sheet shape. The reflection is characterized by medium-weak amplitude, good continuity and parallel structure, reflecting mudstone and shale deposits distributed stably in lowenergy environment (Figure 3). The lithology is dominated by marl and dark mudstone (Figure 4a), with horizontal bedding, with radiolaria, sponge spicule and other fossils observed. TJ7 well, TJ8 well, TJ5-1 well and TJ5-2 1 well all reveal carbonate basin facies, in which the lithology of TJ5-1 Well is black mudstone mixed with argillaceous dolomite, with grain bedding.

\subsection{Platform margin facies}

The platform margin facies lies between the deep water shelf and the shallow carbonate platform facies, and the sedimentary boundary is above the wave strike surface. With strong wave action and high water energy, the platform margin facies is a subtidal high-energy facies belt, which is distributed in Cambrian-Ordovician in 
Tadong area. The platform margin facies can be further divided into platform front slope, platform margin reefbeach complex and mud mound. On the seismic profile, it shows a hillock reflection seismic phase, with weak amplitude, weak continuous chaotic or disordered internal reflection structure and continuous top reflection with medium-strong amplitude (Figure 3).

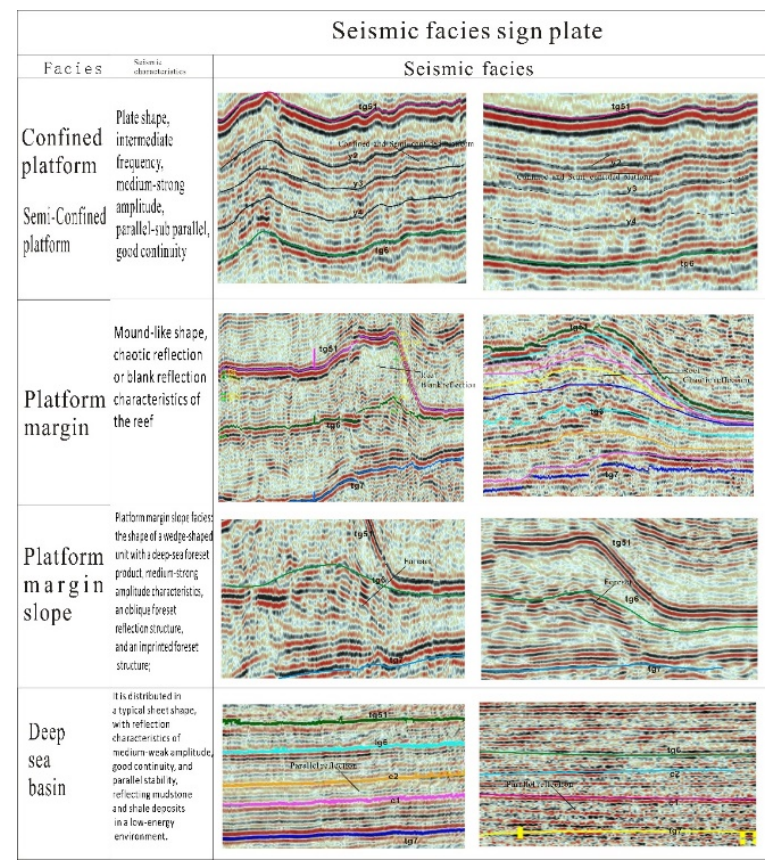

Fig. 3. Seismic facies characteristic chart of CambrianOrdovician main sedimentary facies in Tadong area.

\subsubsection{Platform front slope facies}

The platform front slope facies is located in the slope zone of the platform edge near the shallow sea basin, and the sedimentary interface is above the wave strike surface, with a water depth ranging from zero to tens of meters, and the facies belt is narrow, with an average width of more than ten kilometers, but it extends far in the longitudinal direction. Its lithology is dominated by dark gray argillaceous limestone and argillaceous cloud limestone mixed with black mudstone (Figure 4b). A large number of collapsed breccias are developed at the foot of the slope, which is an obvious sedimentary feature of this facies belt, and is represented by Turshaktag Formation of TJ5-2 well and TJ5-1 well. On the seismic profile, it mainly shows the continuous reflection seismic facies with medium amplitude (Figure 3).

\subsubsection{Reef-beach complex and mud mound at platform margin}

The reef-beach complex and mud mound at the platform margin are located in the slope of the platform margin. The sedimentary interface of the reef-beach complex is above the average wave strike surface, more than ten meters above or below sea level. The wave action is strong, and a narrow medium-high energy facies belt is formed. The lithology of platform margin beach is mainly granular limestone (especially sparkly granular limestone). All sequences of Penglaiba Formation, Yingshan Formation to Yijianfang Formation of Ordovician in Gucheng area (TJ11, TJ13, TJ13-1 and TJ13-2 wells) and Luoxi area (TJ6 1 well) have typical platform margin facies characteristics. High-energy sand debris and bioclastic beach are widely developed at platform margin (Figure $4 \mathrm{c}, \mathrm{d})$, which are mostly composed of granular debris and are of granular beach. Grain cuttings are mainly raw cuttings, sand cuttings and oolites, followed by pellets. Most organisms are echinoderms, brachiopods, ostracods and gastropods. There are small trough-shaped cross bedding and vertical wormholes, and the phenomenon of layer scouring is widespread. When the platform margin beach was formed, the hydrodynamic energy was strong, and the beach was usually distributed around the platform margin in a belt shape. The reef-beach complex has obvious outline on the seismic profile, especially in the areas where reef-building organisms are active and reef uplift is obvious, which are often shown as the external mound shape, while the internal reflection is often chaotic or non-reflective due to energy shielding. For example, in the front edge of Cambrian reef-beach complex on the edge of Gucheng platform where TJ11 well is located, multiple sets of biological mound-beach bodies are laterally deposited and migrated to form a composite Sshaped or imbricate-shaped prestack structure with low angle. The Luoxi platform margin also shows obvious uplift characteristics in seismic profile, and the platform margin beaches developed in different CambrianOrdovician periods are superimposed in the form of progradation and accretion.
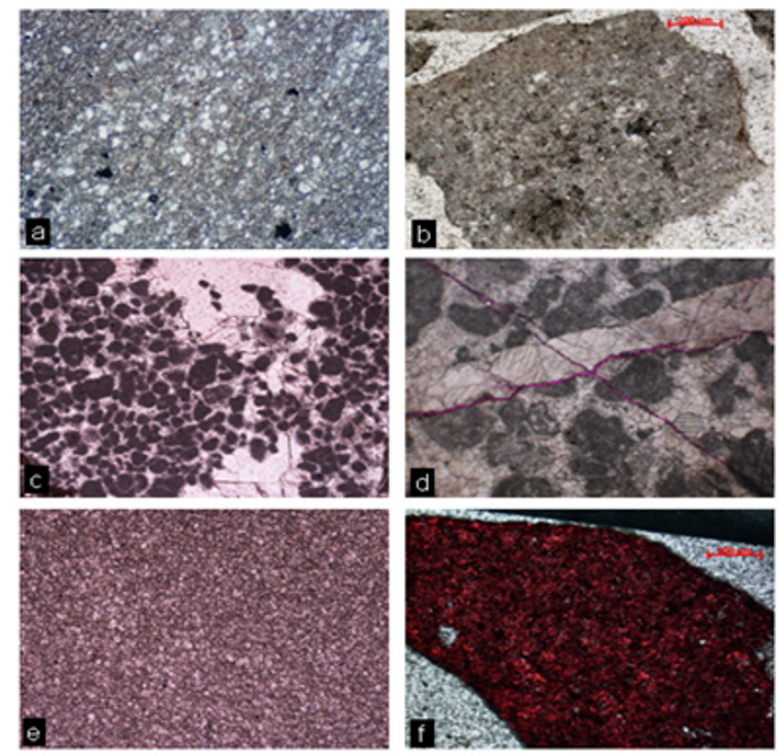

Fig. 4. Microscopic photos of different sedimentary facies in Tadong area. (Note: a. Silty limestone of basin facies, TJ8 well, $4569 \mathrm{~m}$; B B. Muddy powder crystalline dolomitic limestone of platform front slope facies, TJ13-2 well, 5598m, Tumuxiuke Formation; C. Reef-beach complex and mud mound at platform margin, GJ13-1 well $6192.3 \mathrm{~m}$, silty-mesomorphic dolomite; D. Platform margin sparkly sandy limestone, LJ6 well, 4994.96m, p; E. Semi-confined platform silty dolomite, TJ13-1 well, 6499m, p; F. Microcrystalline limestone of limited platform, TJ13-1 well, 6767m,). 


\subsection{Platform facies}

Tadong carbonate platform facies includes Gucheng platform and Luoxi platform, which are mainly distributed in the west of Manjiaer Sag and the south of Kuruktag. Gucheng platform extends from west to east to basin area, while Luoxi platform extends from east to west to basin area. On seismic profile, the platform facies shows parallel and continuous reflection facies with moderate and strong amplitude (Figure 3).

\subsubsection{Open platform facies}

Open platform develops within the platform, which refers to shallow sea with good seawater circulation and normal salinity, and its water energy is low and its organisms are developed. Open platform facies developed in various periods from Cambrian to Ordovician, mainly distributed in the east and west ends of Tadong area. Except for the Middle and Late Ordovician, the eastern strata were denuded in other periods, and open platform facies was not developed. The sedimentary environment of this sedimentary facies is shallow, ranging from several meters to tens of meters, with vast sea area, medium water circulation and salinity close to normal or slightly higher. This sedimentary environment is suitable for the growth of all kinds of organisms except those with narrow salinity. Rock types are mainly granular limestone and marl, with occasional terrigenous clastic deposits such as mudstone and siltstone. The species and quantity of organisms are abundant, and most of them are normal salinity organisms. It can be further divided into intra-platform granular beach, inter-beach sea, intra-platform algae reef (mound) and inter-mound depression. The lithology of the inner beach (inner beach) of the platform is mainly granular limestone, and there are brilliant granular limestone and plaster granular limestone according to the different hydrodynamic strength. The inner beach is represented by Yijianfang Formation of Gl 1 well, and the scale distribution of the beach is limited.

\subsubsection{Semi-confined platform facies}

Semi-confined platform facies mainly developed intraplatform beach and inter-beach sea, which developed in the Early Cambrian and Late Cambrian, and distributed in the eastern side of the Gucheng nose in Tadong area. This facies belt is located inside the open platform facies belt, and the seawater circulation is not smooth. During the Early Cambrian, a set of rocks was mainly deposited, which was mainly composed of dark gray thin-layer silty dolomite and muddy dolomite, mixed with sand cuttings and gravelly dolomite. Late CAMBRIAN is dominated by dark gray silty limestone and dark gray algal microcrystal dolomite, with argillaceous laminae. Texture develops, often with mud cracks, stromatolites and other structures. Syngenetic silty-fine dolomite is developed in the upper part of Penglaiba Formation in TJ13-1 well, while highenergy sparkly sandy limestone, oolitic limestone and low-energy mud sparkly limestone are developed in the lower part (Figure 4e), showing a semi-confined platform sedimentary environment with unsmooth water flow and coexistence of high and low-energy lithofacies.

\subsubsection{Limited platform facies}

The confined platform mainly developed tidal flat, lagoon and barrier beach bar, while the Upper Cambrian was mainly confined platform facies, which evolved from the semi-confined platform in the Middle Cambrian. The sedimentary environment of the sedimentary facies belt is closed, low energy, inactive seawater circulation and high salinity. The rock types are mainly dark gray, brown gray dolomite, gypsum dolomite mixed with black mudstone and purplish red argillaceous dolomite. Local gypsum-salt rock lumps and dry cracks are found. The content of biological debris is low, mainly blue-green algae and ostracods with wide salinity. Tidal flat develops at the local high terrain, which is especially beneficial to the development of tidal flat during the period of sea level decline or relatively stable period. It mainly includes the supratidal zone and intertidal zone. In this area, the tidal flat is deposited with thin layers of light gray silty dolomite and plaster limestone, and horizontal bedding and stromatolites are developed. The upper CAMBRIAN developed quasi-contemporaneous dolomite formed in early diagenetic stage, recrystallized dolomite formed by later diagenetic transformation, and microcrystalline limestone in low-energy environment, showing limited platform deposits with limited water flow and low energy (Figure. 4f).

\section{Evolution of sedimentary system}

\subsection{Early Cambrian}

Early Cambrian Tadong area was dominated by deepwater basin facies, with a large basin area, and its sedimentary center was near Md 1 well, and its lithology was mainly black mudstone and siliceous rock. The platform margin slope facies was developed on both the east and west sides of the basin, and the Lunnan-Gucheng slope facies was narrow and banded in the north-south direction, with an average width of about $28 \mathrm{~km}$. The slope of the Luoxi slope belt was relatively gentle, with a width of about $15 \mathrm{~km}$. The shallow sea shelf facies developed locally (Figure 5).

\subsection{Middle Cambrian}

In Tadong area of Middle Cambrian, large-scale regression began, and the development area of deep-sea basin facies decreased, but Manjiaer Sag was still the sedimentary center in this period. Shallow shelf facies and slope facies are widely developed between platform and deep-water basin, and platform margin facies is distributed in narrow bands on both sides of the basin. Large-scale regression led to the successive migration of various facies belts in Tadong area to the basin. In the Gucheng slope facies area, platform margin reef-beach deposit (Figure 6) appears, and its lithology is mainly 
clotted lime mud mound, which is the identification mark of early platform margin facies belt.

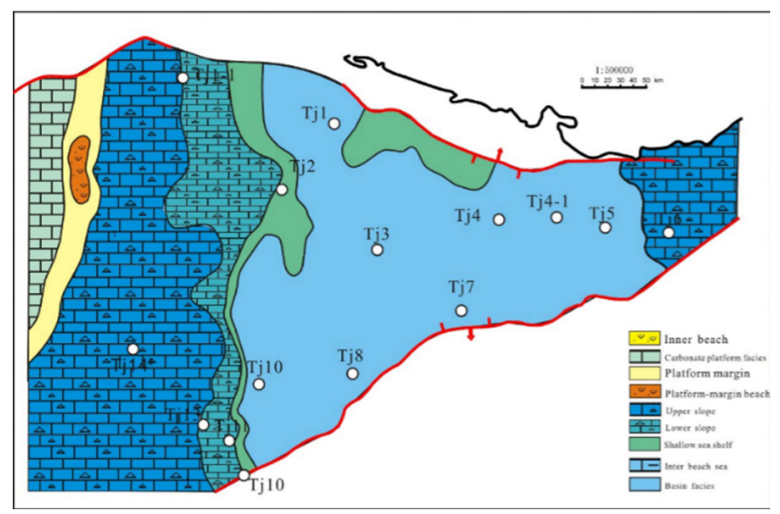

Fig. 5. Sedimentary facies map of Early Cambrian in Tadong area.

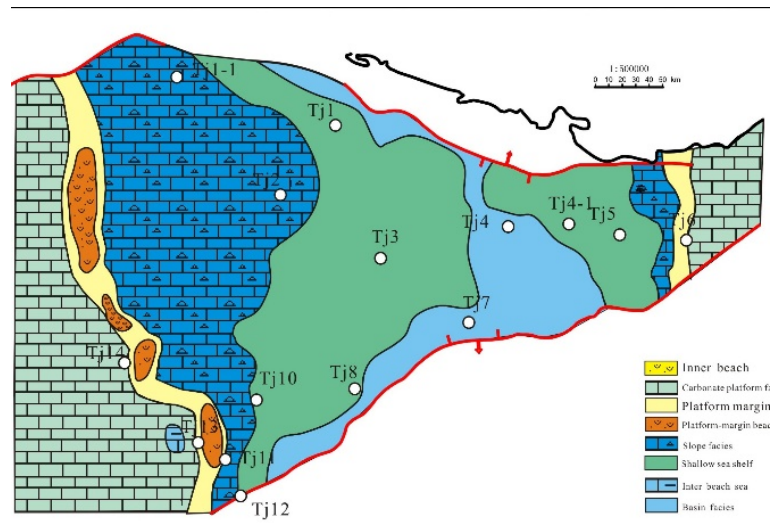

Fig. 6. Sedimentary facies map of Middle Cambrian in Tadong area.

\subsection{Late Cambrian}

The area of trough and basin in Late Cambrian continued to decrease, and shallow sea shelf facies developed mainly between platform and deep-water basin, with basin facies seen locally, and platform marginal facies belt and reef-beach complex continued to migrate towards the basin (Figure 7). The platform margin and platform margin beach in Gucheng area were developed, and the shoal facies deposits were the main ones. Platform front slope facies was developed around TJ5-1 well and TJ5-2 well, which is mainly composed of collapse sedimentation and carbonate turbidity current sedimentation, and TJ6 well is characterized by typical platform edge shallow beach sedimentation.

\subsection{Early and Middle Ordovician}

In the early Ordovician, the sea level began to rise slowly, the scope of basin facies expanded, the scope of shallow sea shelf facies decreased, and the sedimentary center and boundary of each facies belt moved westward (Figure 8). The turbidite, marl, carbonaceous mudstone and radiolarian silicalite of semi-deep-deep sea facies were deposited in the Early-Middle Ordovician of TJ7 well and TJ8 well. The carbonate gentle slope in GuchengLundong area gradually developed into platform margin with obvious slope break, and reef-beach complex with high-energy facies belt developed at the platform margin. At this time, shelf-building organisms began to appear in platform margin mound-beach facies, and mud mound deposition in the middle and late Cambrian evolved into bio-mound, bio-beach, algae reef and other deposits. The Middle-Lower Ordovician in TJ11 well is mainly composed of sparkly sandy limestone, algal sandy limestone and oolitic limestone, and trilobite fragments, spines and a large number of shrubby algae fragments with algae reef function are found in rock slices, reflecting the strong hydrodynamic conditions and the sedimentary characteristics of platform margin beach facies. In the early-middle Ordovician, the Luoxi slope break belt basically did not migrate, and the reef beach was also developed. The Middle-Lower Ordovician in TJ6 well is mainly composed of glutenite limestone, oolitic limestone and bioclastic limestone, with algal fragments, which is a typical platform margin high-energy granular beach deposit.

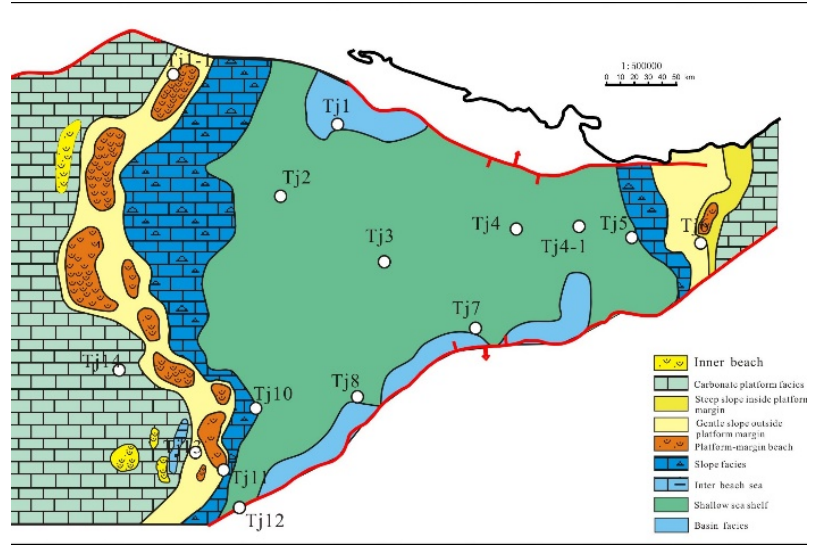

Fig. 7. Sedimentary facies map of Late Cambrian in Tadong area.

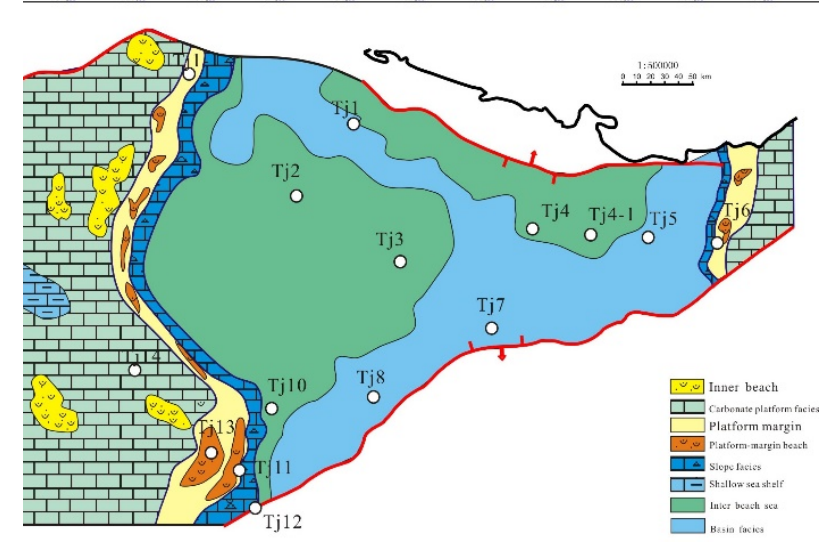

Fig. 8. Sedimentary facies map of Early Ordovician in Tadong area. 


\section{Conclusion}

(1) Cambrian and Middle-Lower Ordovician in Tadong area are equivalent to second-order sequences, which are generally composed of a large transgressive-regressive cycle, and are divided into 12 third-order sequences. Each third-order sequence is mainly composed of transgressive and high-level domains, and argillaceous limestone/dolomite or mudstone deposits are developed during the maximum transgressive period. The carbonate platform (platform margin) beaches in the high-level domain of the third-order sequences of Penglaiba Formation and Yingshan Formation in the Middle and Lower Ordovician are widely developed, which is a favorable reservoir development period. The Cambrian third-order sequences are mainly composed of transgressive and high-level domains, and the carbonate platform beach or reef (mound) beach complexes in SQ_C2, SQ_C3-1, SQ_C3-2 and SQ_C3 sequences are developed, which can form favorable reservoirs.

(2) In Tadong area (Gucheng platform and Luoxi platform), the early Cambrian mainly consists of platform margin slope facies-deep water basin sediments, while the middle and late Cambrian consists of (semi) limited platform facies-open platform-platform margin hill (reef) beach facies-platform margin slope facies-basin facies. Compared with the middle Cambrian, the sea level in the late Cambrian decreased further and the platform margin moved into the basin. Transgression began in Early Ordovician, and the sedimentary pattern was open platform-platform margin beach facies-platform margin slope facies-basin facies from west to east.

\section{References}

1. Li Wenhou, Chen Qiang, Li Zhichao, et al. Lithofacies palaeogeography of early Paleozoic in Ordos region [J]. Journal of palaeogeography, 14 (1): 85-100 (2012).

2. Feng Zengzhao, Bao Zhidong, Wu Maobing, et al. Cambrian lithofacies palaeogeography in Tarim area [J]. Journal of palaeogeography, 8 (4): 427-439 (2006).

3. Feng Zengzhao, Bao Zhidong, Wu Maobing, et al. Ordovician lithofacies palaeogeography in Tarim area [J]. Journal of palaeogeography, 9 (5): 447-460 (2007).

4. Yang Yongjian, Liu Jiaduo, Tian Jingchun, et al. Congratulations on the lithofacies palaeogeography of Cambrian sequence in Tarim Basin [J]. Natural Gas Geoscience, 22 (3): 450-459 (2011).

5. Yu Kuanhong, Zhenkui jin, Li Peng, et al. Analysis of Cambrian-Ordovician lithofacies palaeogeography in Tadong area [J]. Northwest Geology, 43 (4): 113118 (2010).

6. Liu Yang. Study on sedimentary facies characteristics of Cambrian reservoirs in Tadong area [J]. Journal of Yangtze University (Natural Edition), 11 (31): 17-20 (2014).
7. Xu Kang, Liu Guangxiang, Hu Wenxuan, et al. Distribution and sedimentary facies of reefs and beaches in the Upper Ordovician sequence framework in Tazhong area [J]. Petroleum Geology and Development of Daqing, 37 (2): 27-30 (2018).

8. He feng, Lin changsong, Liu jingyan et al. sedimentary characteristics and main controlling factors of carbonate rocks in Gucheng area [J]. Special oil and gas reservoirs, 23 (5): 17-19 (2016).

9. Zhang Tao, Gui Xiangbin, Wang Shuyi, et al. Characteristics and genesis of reef-beach dissolved pore reservoirs in Yijianfang Formation of Ordovician in Tahe Oilfield [J]. Petroleum and Natural Gas Geology, 25 (4): $462-466$ (2004).

10. Yang Haijun, Li Yong, Liu Sheng, et al. Main understanding of division and correlation between middle and upper Ordovician in Tazhong area [J]. Xinjiang Petroleum Geology, 21 (3): 209-212 (2000).

11. Kang Zhijiang and Li Hongkai. Characteristics of Ordovician carbonate reservoirs in Tahe Oilfield [J]. Petroleum Geology and Development of Daqing, 33 (1): 21-26 (2014).

12. Lv xiuxiang. Characteristics of Ordovician carbonate reservoirs in Tazhong area and their hydrocarbon significance [J]. Journal of $\mathrm{Xi}^{\prime}$ an Shiyou university (natural science edition), 19 (4): $72-76$ (2004).

13. Yan Xiangbin, Li Tiejun, Zhang Tao, et al. Differences in formation conditions of Ordovician karst reservoirs in Tazhong and Tahe areas [J]. Petroleum and Natural Gas Geology, 26 (2): 202-207 (2005).

14. Wu guanghui, Li qiming, Zhang baoshou, et al. Structural characteristics and exploration fields of slope break zone of Tazhong No.1 fault [J]. Acta petrolei sinica, 26 (1): 27-30 (2005). 